\title{
CONGENITAL ELEPHANTIASIS ASSOGIATED WITH CONSTRICTION BY ANOMALOUS BANDS
}

\author{
A. W. Farmer, Toronto, Canada
}

From the Surgical Service of the Hospital for Sick Children, Toronto

Congenital constricting bands of the extremities are not uncommon. These bands may take the form of complete, or of incomplete, circles of varying depth. They vary from sloping concavities of the skin and subcutaneous fat, to sharp indentations with firm circular compression. The fingers and toes are most often affected. Multiple constrictions may be present, encircling either the digits or the limbs. Associated deformities are often found. There may be absence of part of a toe, finger, leg, or arm; or varying degrees of fusion of the digits to one another; or absence of the interphalangeal joints, with one or two long phalanges instead of three; or rudimentary phalanges with distorted interphalangeal joints; or points of deep dimpling of the skin. Unrelated congenital abnormalities may also be present, such as cleft lip and cleft palate. That all these anomalies may be present in one individual is demonstrated in Figs. 2 and 3 , which show a child with hare lip (photograph taken after repair), cleft palate, incomplete and complete absence of digits, fusion of phalanges, webbing of fingers, equinovarus deformity of one foot, incomplete and complete constricting bands of one leg, and points of dimpling.

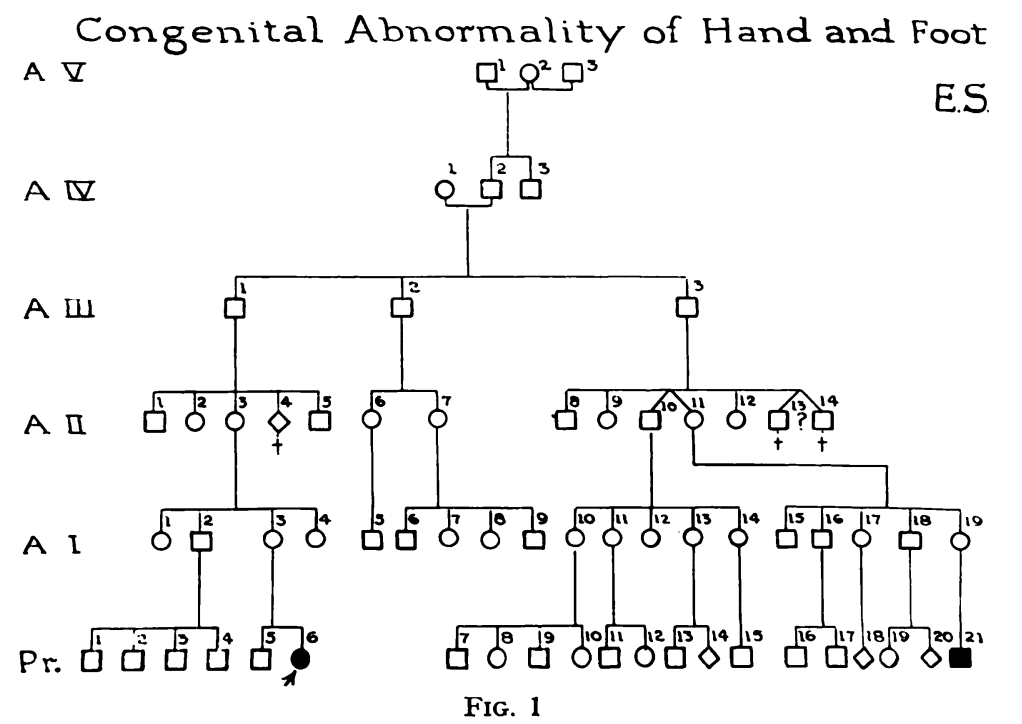

Pedigree of two children with marked congenital anomalies of the feet and hands, one with a loose circular constriction of the forearm (see Fig. 4).

Familial and pre-natal influences-Discussion of the pre-natal influences which bring about these deformities will not be undertaken; the author has nothing new to add. Fig. 1 shows the pedigree of two children with marked congenital anomalies. One exhibited abnormalities of both feet and one hand with a loose circular constriction of the forearm (Fig. 4). The other was a distant cousin who was not examined, but of whom a photograph showed absence of digits and part of the thumb of one hand. The tracing of such deformities among ancestors is a most difficult if not impossible task, demanding intense effort on the part of interested investigators; little significance must be attached to failure to secure evidence of such familial tendencies. While in one individual patient, ring-like depression 


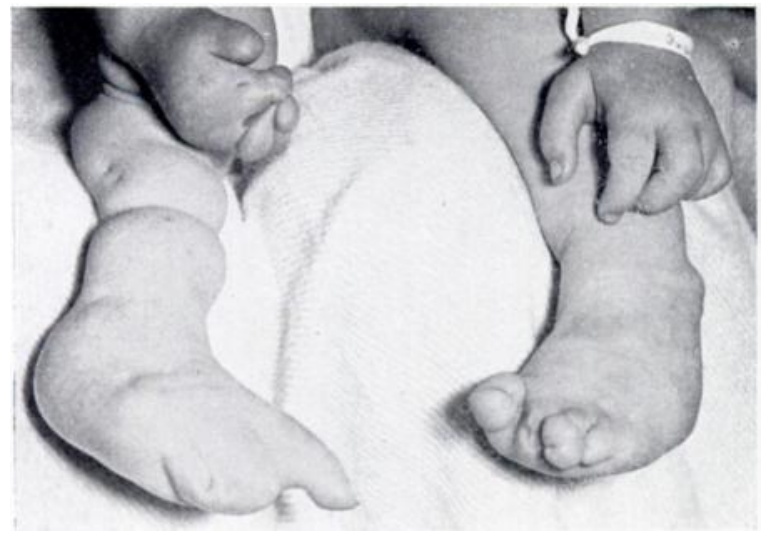

FIG. 2

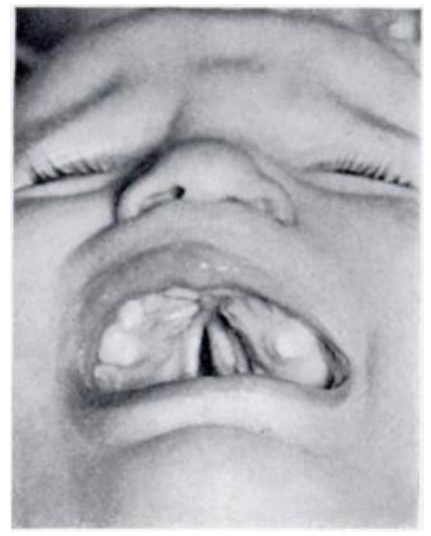

I.IG. 3

Irultiple congenital anomalies in one child, including hare lip, cleft palate, absence of digits, fusion of phalanges, webbing of fingers, equinovarus deformity of the foot, complete and incomplete constricting bands of one leg, and congenital dimpling.

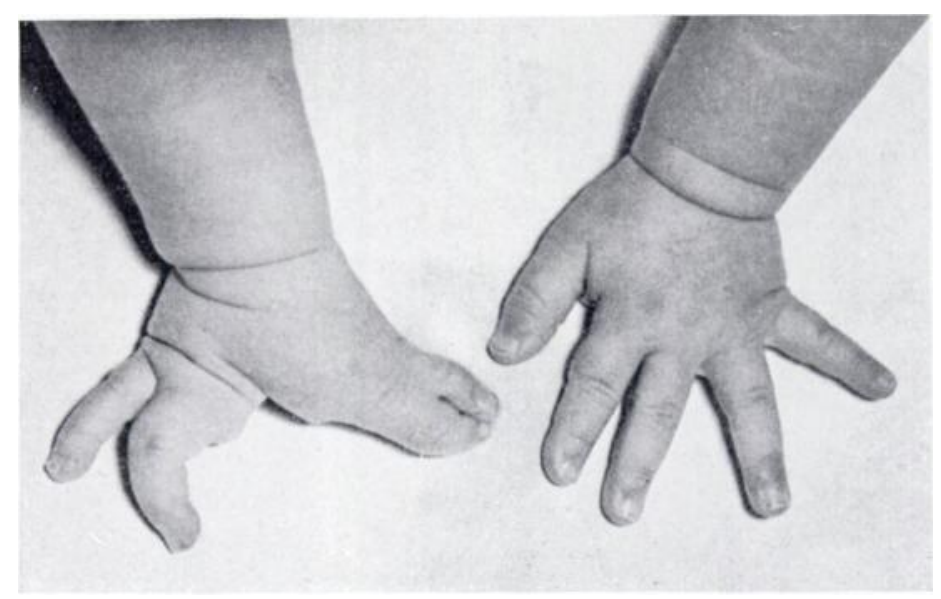

Fig. 4

Congenital anomalies of the right hand with loose circular constriction of the forearm (see pedigree-Fig. 1).
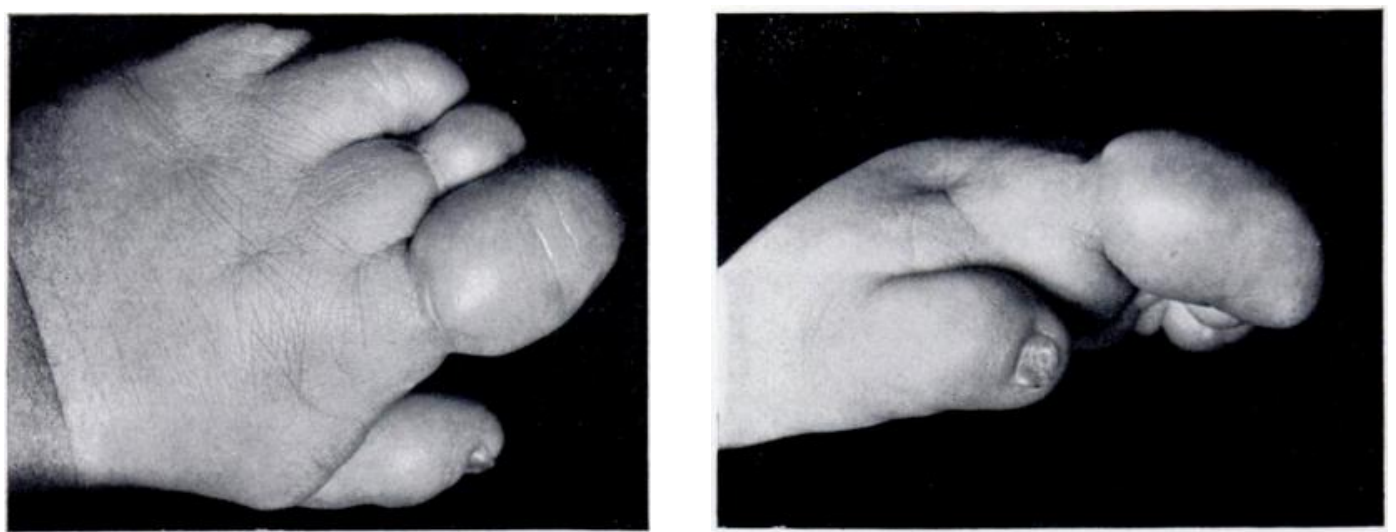

FIG. 5

Constricting band of the digits with marked subcutaneous thickening of the index finger.

vol. $30 \mathrm{~B}$, No. 4 , NOVEMBER 1948 
of an extremity may be the only anomaly found, it is probably the least significant manifestation of an inherited tendency contributing to the production of a variety of more obvious and disabling deformities.

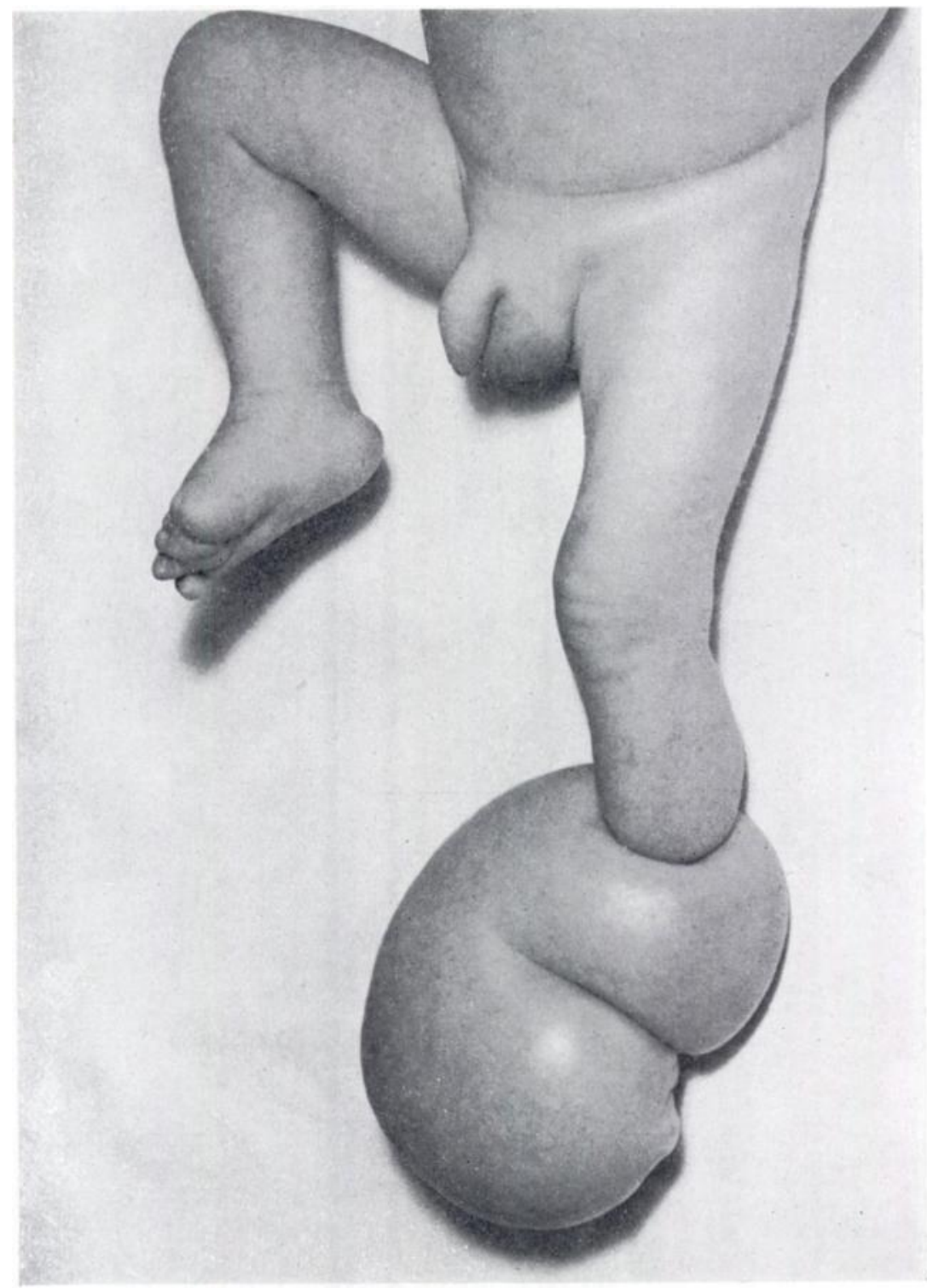

FIG. 6

Male child, aged four months, with multiple congenital anomalies of the hand and feet, and with enormous swelling and lymphoedema of the left foot distal to a tight constricting band encircling the limb above the malleoli. Operative treatment was carried out as indicated in lig. 7.

Subcutaneous thickening and lymphoedema-Distal to a constricting band there may be considerable increase in the thickness of subcutaneous tissues. This has often been noted in the fingers (Fig. 5). The blood flow into such enlargement of the digits is good, and there is seldom increase in the lymph. On the other hand when there is a tight constricting band 
higher in the limb, astonishing degrees of lymphoedema may sometimes occur (Bize and Grisel 1904). The chief purpose of this publication is to report the treatment of such a case.

Case report-A male child, four months of age, was admitted to hospital with multiple congenital anomalies of the hands and feet. There was no history of deformity in the child's ancestors. The right hand showed fusion of the tips of the middle, index, and ring fingers. In each finger there was one large and one small phalanx. The thumb had one phalanx. The left hand showed absence of the tips of the fingers, with one normal phalanx for each finger. The thumb was normal. The big toe and parts of the other toes were absent from the right foot. The left foot presented a tight constricting band which wholly encompassed the limb above the malleoli (Fig. 6). Below this encirclement was a tremendous enlargement. The skin was shiny and tight, and it had a transparent, waxy appearance. The tissues were firm. There was no pitting on pressure. After digital compression there was immediate return to the original shape. Radiographs showed very great soft tissue thickening, but there was no abnormality of the bones.

Operative treatment-The condition was treated by three operative procedures carried out at intervals of approximately two weeks. The first two operations were similar in nature: first, the anterior half, and then the posterior half, of the constricting band was excised. In each case a strip of tissue, one quarter of an inch wide and half the circumference of the limb, was excised in the line of the band (Fig. 7). Transposition of flaps was accomplished by means of a " $Z$ " plastic manoeuvre from the normal area above, into the abnormal area below, and vice versa. This was performed on so large a scale as to remove the indentation from the whole circumference of the limb. At a third-stage operation, skin and subcutaneous tissues were removed from the dorsum of the foot down to the deep fascia. Part of the skin was
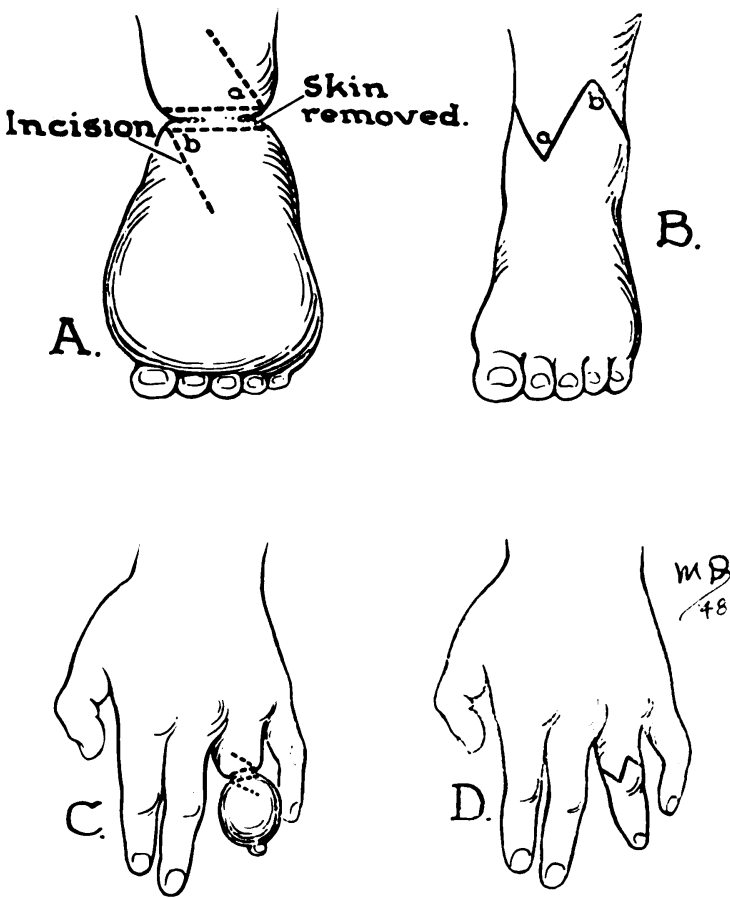

FIG. 7 converted into a free, full-thickness graft by excision of all subcutaneous fibrous tissue. It was then replaced and a pressure dressing was applied. In one area there was some loss of skin which was replaced later by a split-skin graft.

Laboratory examination of tissue fluid-At the original operation, when the incision was first made, clear fluid flowed from the wound as blood might flow from a large vein. Four test tubes were filled with this liquid which on analysis showed a serum protein content of $\mathbf{2 \cdot 2}$ grams per cent. Laboratory reports showed that only albumin was present. The fluid did not clot even after several hours. Microscropic examination showed no more than a few lymphocytes.

Histological examination of removed tissue-The great increase in thickness of the epidermis of the skin from the dorsum of the foot is shown in Fig. 12. In a section of the deeper tissues large lymph channels can be seen clearly (Fig. 13).

Vol. $30 \mathrm{~B}$, No. 4 , NOVEMBer 1948 


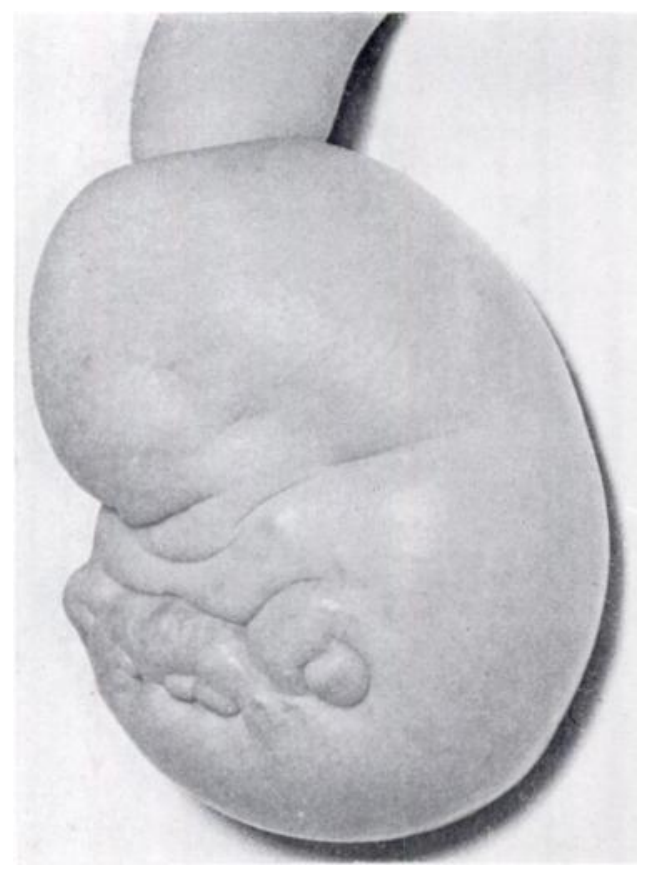

Iili. S

Photograph of the foot, in the case reported before operative treatment.

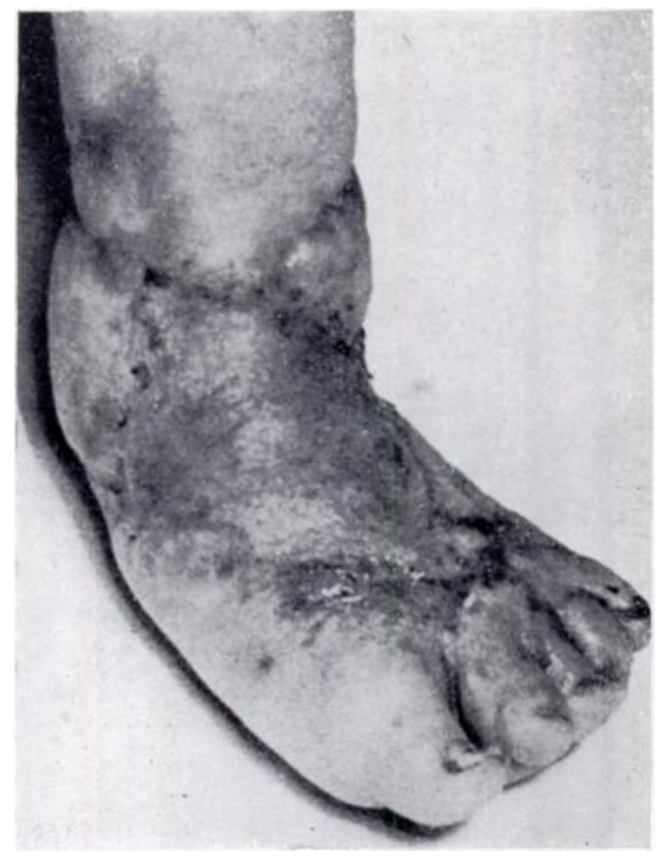

FIG. 10

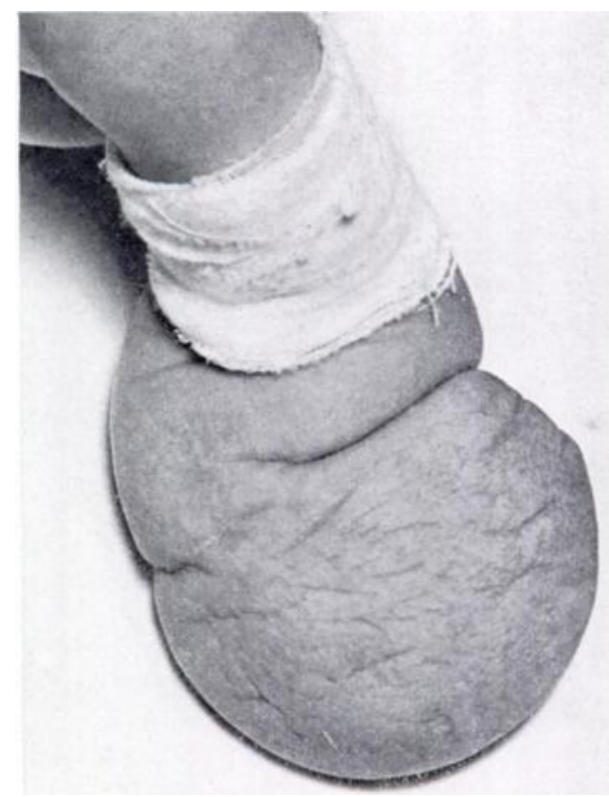

Fili. 9

Within a few days of the first operation there was remarkable shrinkage of tissue.

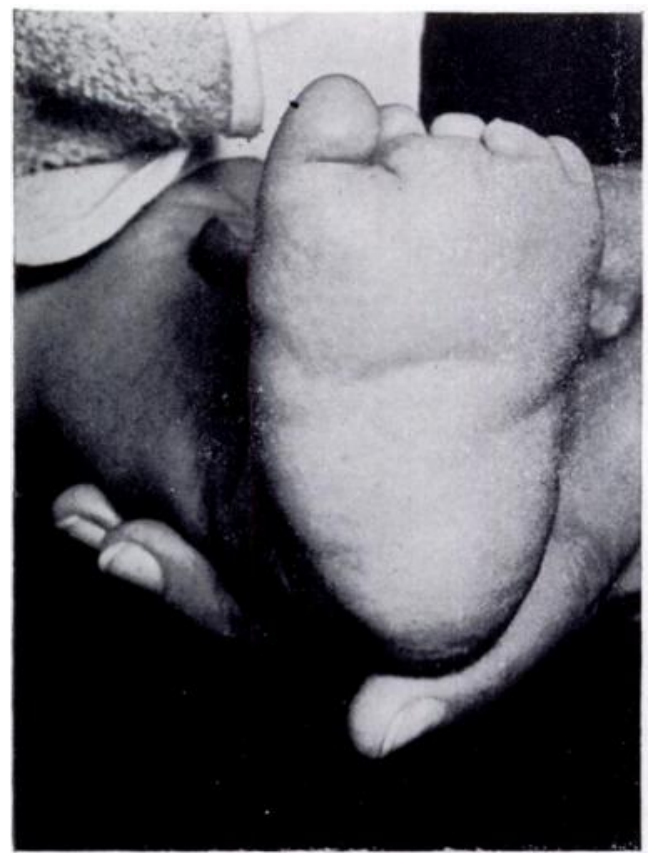

1.16. 11

After the completion of operative treatment, including two " $Z$ " plastic resections of the constricting band, resection of skin and subcutaneous tissue from the dorsum of the foot, and whole thickness and split-skin grafting, the foot is almost normal in appearance and function. 
Post-operative course-The condition of the foot before operation is shown in Fig. 8. It was almost impossible to recognise the shape of the toes. Within a few days of the first operation there was remarkable shrinking of tissues (Fig. 9). By the time the patient was discharged from hospital, after the third operative procedure, the foot was almost normal in appearance (Fig. 10). Re-examination several months later showed that the cosmetic appearance was still satisfactory and function was excellent (Fig. 11). There had been no recurrence of swelling or enlargement of the limb.

\section{DISCUSSION}

Enlargement of an extremity at birth may be due to a number of factors other than constricting bands. Cooperstock (1939) indicated that the three chief causes of congenital enlargement were: 1) lymphangiectasis; 2) haemangiectasis and congenital arteriovenous

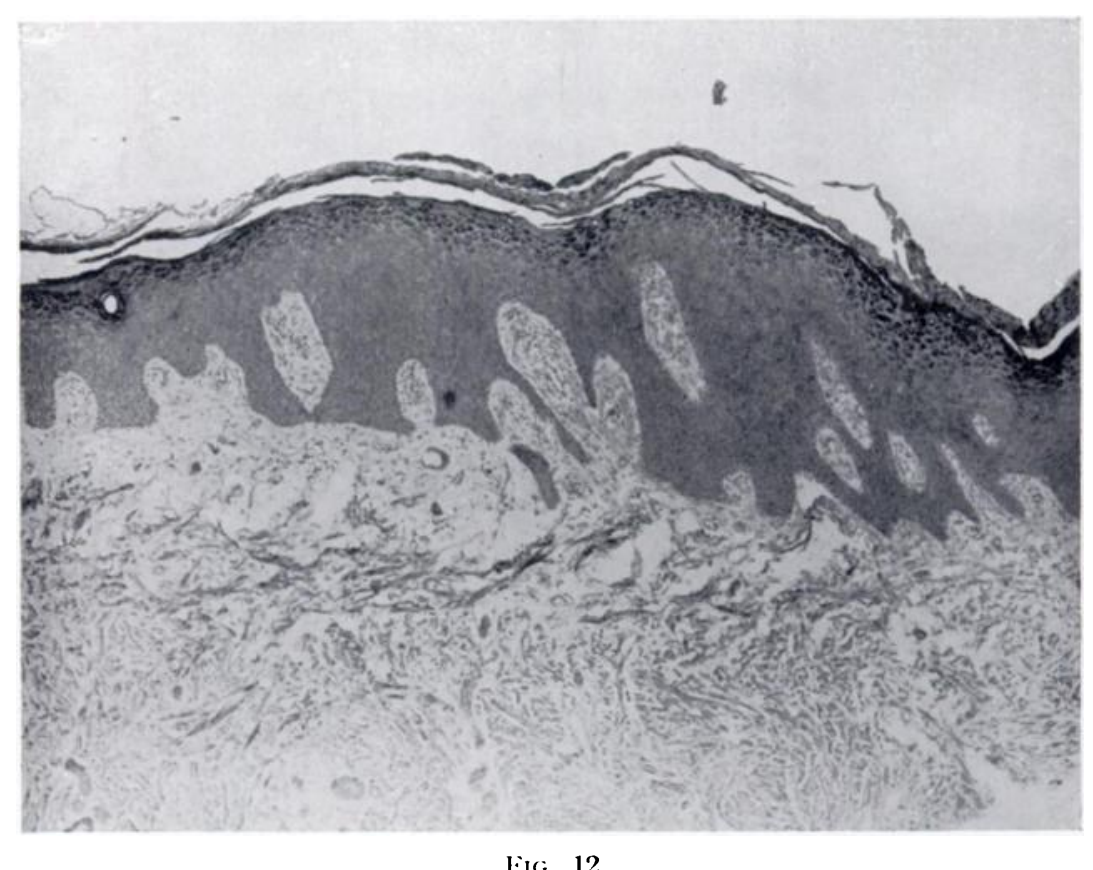

Section of skin from the dorsum of the foot in the case shown in liig. 6 . There is great increase in the thickness of the epidermis.

anastomoses; 3) Recklinghausen's neurofibromatosis. In all forms of elephantiasis there is overgrowth of connective tissue. It has been suggested by Homans (1940) that the proteinised fluid acts as a tissue culture medium and encourages fibrosis. In the case here reported, the elephantiasis was undoubtedly due to blockage of veins and lymphatics in the region by a tight encircling indentation. It is unbelievable that this could be the result of pressure from an amniotic band about the limb. Such is discussed by Ballantyne (1902) who noted that "pictures of them are to be found in the older works on monstrosities."

The use of the " $Z$ " plastic manoeuvre for the correction of such constrictions is not new. Ferris Smith (1946) warned against the use of incisions around the entire circumference of the constriction in cases without lymphoedema. It was indicated that in one such case swelling still persisted many years after operation.

VOL. $30 \mathrm{~B}$, No. 4 , NOVEMBER 1948 


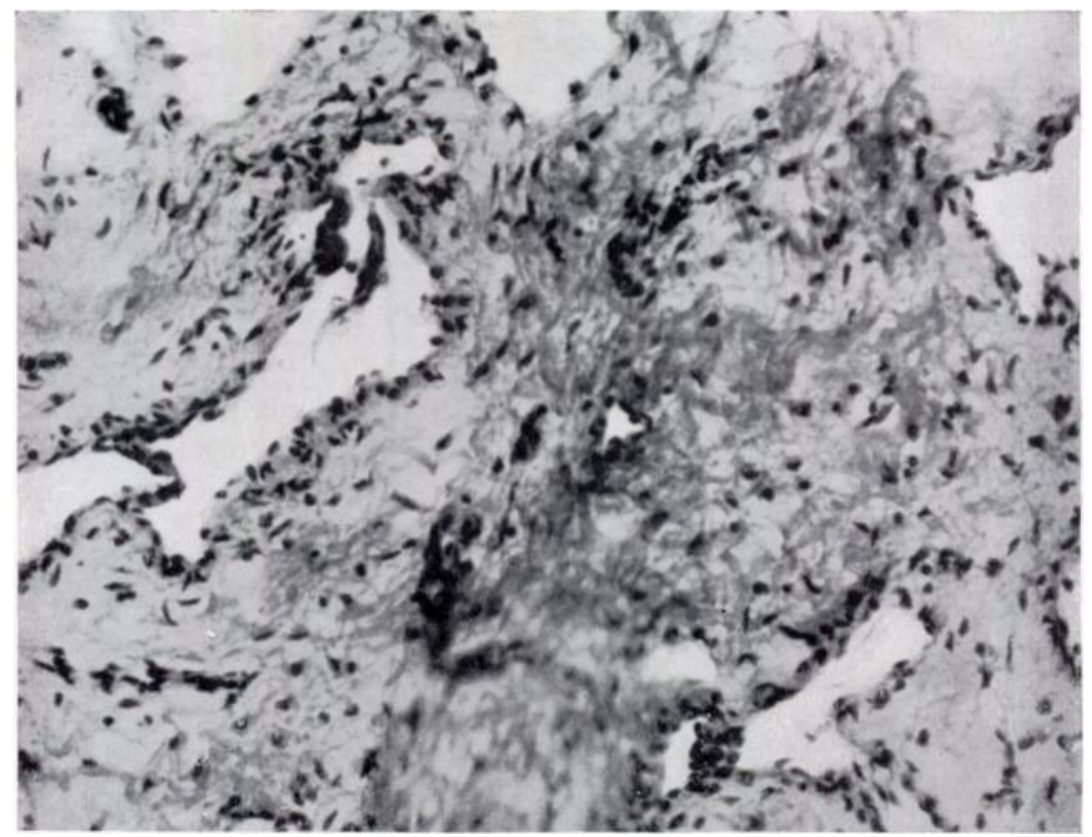

Fig. 13

Section of subcutaneous and deeper tissues from the foot in the case shown in Fig. 6. Large lymph channel can be seen clearly.

\section{SUMMARY}

Congenital anomalous bands of the extremities are variable in position, depth, and in the completeness of their encirclement. They represent one of a group of abnormalities which are often present in the same individual. Cases associated with gross lymphoedema are rare. The treatment of such a case is presented.

\section{REFERENCES}

Ballantyne, J. W. (1902): A Manual of Antenatal Pathology and Hygiene: The Foetus. New York: William Wood and Company.

Bize and Grisel (1904): De l'elephantiasis congenital. Revue d'Orthopédie, 5, 459.

Cooperstock, M. (1939): Congenital Enlargement of the Extremities. American Journal of Diseases of Children, 57, 309.

Homans, J. (1940): Lymphedema of the Limbs. Archives of Surgery, 40, 232.

Smith, F. (1946): Multiple Excision and Z Plastics. Plastic and Reconstructive Surgery, 1, 170. 